\title{
Analisis Perbandingan Performa dari Enhanced Ant AODV dan Enhanced Ant DSR Berdasarkan Parameter Quality of Service
}

\author{
${ }^{1}$ Wahyu Suadi, ${ }^{2}$ Radityo Anggoro \\ Departemen Teknik Informatika Institut Teknologi Sepuluh Nopember, Indonesia \\ Email: ${ }^{1}$ wsuadi@if.its.ac.id, ${ }^{2}$ onggo@if.its.ac.id
}

\begin{tabular}{l}
\hline Tersedia Online di \\
\hline http://www.jurnal.unublitar.ac.id/i \\
ndex.php/briliant \\
\hline \\
\hline Sejarah Artikel \\
\hline Diterima pada 11 April 2020 \\
Disetujui pada 15 April 2020 \\
Dipublikasikan pada 30 Mei 2020 \\
Hal. 410-416 \\
\hline \\
\hline Kata Kunci: \\
\hline MANET; Quality of Service \\
(QoS); Enhanced-Ant AODV; \\
Enhanced-Ant DSR \\
\hline DOI: \\
\hline http://dx.doi.org/10.28926/briliant. \\
v3i4.456
\end{tabular}

\begin{abstract}
Abstrak: Salah satu masalah yang dihadapi Mobile Ad-hoc Network (MANET) adalah pemilihan rute optimal dengan mempertimbangkan Quality of Service (QoS). Pada penelitian - penelitian sebelumnya telah ditemukan metode routing protocol dengan mempertimbangkan quality of service. Metode routing protocol ini yaitu Enhanced-Ant Adhoc ondemand Vector (AODV) dan Enhanced-Ant Dynamic Source Routing (DSR) yang merupakan metode yang menerapkan algoritma Ant-Colony Optimization (ACO). Kedua metode ini menghitung nilai pheromone dengan mempertimbangkan beberapa faktor QoS. Berdasarkan kedua metode tersebut, dilakukan perbandingan dengan membandingkan hasil Packet delivery ratio, packet loss ratio, dan endto-end delay. Hasil didapatkan bahwa metode Enhanced-Ant AODV lebih baik daripada metode Enhanced-Ant DSR.
\end{abstract}

\section{PENDAHULUAN}

Salah satu masalah yang dihadapi Mobile Ad-hoc Network (MANET) adalah pemilihan rute yang optimal. Hal ini sulit dilakukan dikarenakan MANET merupakan sekumpulan node yang bergerak dalam suatu jaringan sementara dan tidak memiliki infrastruktur jaringan yang tetap maupun administrasi terpusat. Berbagai metode routing telah ditemukan salah duanya adalah metode Adhoc ondemand Vector (AODV) (C. Perkins, et.al, 1999) dan Dynamic Source Routing (DSR). Kedua metode ini merupakan metode routing yang menggunakan jumlah hop sebagai kriteria dalam pemilihan rute yang optimal (M. Bouhorma, et.al, 2009). Pemilihan rute optimal ini menjadi tantangan baru saat rute harus mencapai suatu kebutuhan Quality of Service (QoS). Telah terdapat metode pengembangan baik dari AODV maupun DSR dalam memenuhi kebutuhan QoS dengan menerapkan metode optimasi Ant Colony Optimazation (ACO). Metode ini bernama Enhanced-Ant AODV (D. Sarkar, et.al, 2018) dan Enhanced-Ant DSR (S. Chatterjee and S. Das, 2015). Pada paper ini akan dilakukan Analisa perbandingan performa antara kedua metode tersebut. Kedua metode protokol ini akan disimulasikan menggunakan ns-2 package dan membandingkan rata - rata dari packet delivery ratio, packet loss ratio, dan end to end delay, dengan berbagai variasi jumlah node.

Kedua metode baik Adhoc on-demand Vector (AODV) maupun metode protocol Dynamic Source Routing (DSR) merupakan merupakan metode protokol 
yang dikategorikan sebagai reactive protocol. Reactive protocol merupakan metode protokol dimana routing table akan diperbaharui hanya saat akan mengirimkan paket atau saat dibutuhkan saja. Pada protokol ini suatu node yang ingin mengirimkan suatu paket ke node tujuan akan mengecek terlebih dahulu routing table yang dimilikinya. Jika rute terhadap node tujuan tidak ditemukan, maka akan dilakukan route discovery untuk menemukan rute node tujuan (A. Zakaria, et.al, 2018).

Dynamic Source Routing (DSR) adalah suatu protocol pada Mobile Ad-hoc Network (MANET) yang bekerja dengan dua mekanisme yaitu route discovery dan route maintenance. Route discovery dilakukan saat node sumber ingin mengirim paket ke node tujuan namun rute belum terdapat pada route cache. Node sumber akan membanjiri jaringan dengan paket RREQ. Node yang menerima paket RREQ pada awalnya akan mengecek node tujuan pada paket tersebut. Jika node tujuan bukan merupakan nodenya, maka paket akan diteruskan setelah sebelumnya ditambahkan ID pada paket RREQ tersebut. Jika node tujuan merupakan nodenya, maka RREQ packet akan diganti typenya menjadi RREP packet dan kemudian paket akan dikirim kembali ke node sumber. Route maintenance dilakukan untuk mendeteksi kerusakan yang terjadi pada rute pengiriman paket. Jika terjadi kerusakan pada rute, maka akan dilakukan pencarian rute alternatif menuju node tujuan (A. Zakaria, et.al, 2018).

Adhoc on-demand Vector (AODV) adalah suatu protokol yang memiliki tiga mekanisme yaitu Route Request (RREQ), Route Reply (RREP), dan Route Error (RRER). Pada proses mencari rute baru paket RREQ akan dikirmkan ke node - node di sekitar node sumber. Jika node yang menerima bukan merupakan node tujuan, maka node tersebut akan memperbaharui routing tabelnya dan membuat link antar node yang mengirimkan paket RREQ tersebut. Kemudian node tersebut akan meneruskan paket ke node berikutnya. Jika suatu node yang menerima paket merupakan node tujuan maka node tersebut kemudian akan mengirimkan Route Reply (RREP) kepada node sumber. Node sumber yang telah menerima RREP paket akan menggunakan rute tersebut untuk mentransmsikan paket. Pada AODV, tahap pemeliharaan rute menggunakan paket Route Error (RRER) (A. Zakaria, et.al, 2018).

\section{METODE}

Pada metode Enhanced-Ant AODV (D. Sarkar, et.al, 2018) ada beberapa faktor yang dipertimbangkan dalam meningkatkan Quality of Service (QoS). Faktor faktor tersebut adalah Link quality, congestion, residual energy, dan number of hops. Pada faktor residual energy, node penghubung akan ditentukan melalui sebuah threshold. Jika node penghubung tidak memenuhi threshold tersebut, maka node tersebut tidak akan dipilih dalam pengiriman data. Begitu pula pada faktor link quality yang mempertimbangkan signal strength, threshold juga akan diberlakukan dalam memilih node penghubung. Oleh karena itu terdapat 2 threshold yang diterapkan dalam metode ini yaitu SIGNAL_THR, nilai threshold pada received signal strength. Jika received signal strength berada dibawah threshold ini maka node tidak akan dipilih sebagai node penghubung. Sedangkan yang kedua adalah RE_THR, nilai threshold pada residual energy. Jika residual energy berada dibawah threshold ini makan node tidak akan dipilih sebagai node penghubung. 
Sedangkan faktor congestion digunakan untuk menilai seberapa pada suatu node dilalui oleh paket. Semakin jarang suatu node dilalui oleh paket maka node tersebut memiliki kesempatan lebih besar untuk digunakan sebagai node penghubung. Faktor terakhir yang dipertimbangkan adalah number of hops dari paket. Seperti halnya metode AODV biasa, rute yang dipilih adalah rute yang memiliki jumlah hop yang minimum. Saat pemilihan next hop dalam proses meneruskan route request ke tujuan, nilai pheromone digunakan dalam penentuan next hop. Penghitungan nilai pheromone dari link node i menuju node $\mathrm{j}$ (PCij) bisa dihitung dengan cara pada Persamaan 1 .

$$
P C_{i j}=\frac{R n_{i j} \times E n_{i j}}{C n_{i j} \times H n_{i j}}
$$

Dimana $\mathrm{Rn}_{\mathrm{ij}}$ adalah received signal strength node $\mathrm{j}$ dari node $\mathrm{i} . \mathrm{En}_{\mathrm{j}}$ adalah sisa energi dari node $\mathrm{J} . \mathrm{Cn}_{\mathrm{j}}$ adalah congestion pada node $\mathrm{j} . \mathrm{Hn}_{\mathrm{ij}}$ adalah number of hops yang dilalui node sumber ke node $\mathrm{j}$ melalui node i. Faktor pertama, received signal strength didapatkan dari node $\mathrm{i}\left(\mathrm{RSS}_{\mathrm{ix}}\right)$ dapat dihitung menggunakan rumus pada Persamaan 2.

$$
\operatorname{RSS}_{i x}=\frac{G_{e} \times G_{i} \times S_{t}}{\left(4 \pi \times \frac{x}{\bar{\lambda}}\right)^{2}}
$$

Dimana $\chi$ adalah panjang gelombang yang digunakan pada MANET. Ge adalah receiving antenna gain, $\mathrm{Gi}$ adalah transmitting antenna gain, dan $\mathrm{St}$ adalah maximum transmitting power dari transmitting antenna. Dari received signal strength yang didapatkan dapat dihitung threshold dari tetangga node dengan menggunakan Persamaan 3

$$
T_{j}=\frac{G_{r} \times G_{t} \times S_{t}}{\left(4 \pi \times \pi \frac{0.9054 R}{\lambda}\right)^{2}}
$$

Dimana $\mathrm{G}_{\mathrm{r}}$ adalah receiving antenna gain pada range $\mathrm{R}$. Threshold ini akan digunakan untuk mempertimbangkan nilai dari Rssix telah melewati threshold tersebut atau belum. Faktor kedua, congestion metric didapatkan dengan menilai panjang antrian (queue) paket pada suatu node. Perhitungan dari congestion metric ini dapat dilihat pada Persamaan 4. Dimana $\mathrm{N}$ adalah jumlah paket dari panjang gelombang $(\chi)$ pada interval $t$.

$N=\chi t$

Faktor ketiga, residual energy didapatkan dengan mempertimbangkan inisial energi dari suatu node dikurangi dengan konsumsi energi pada node tersebut. Hal ini dapat dilihat pada Persamaan 5.

$E_{i}^{\text {Res }}(t)=E_{i}^{0}-C_{t}$

Faktor keempat, number of hops adalah jumlah hop yang dibutuhkan node sumber ke node tujuan pada suatu rute. Setiap kali Route request melewati satu node, jumlah hop akan di increment sebanyak 1. Dari keempat faktor yang diperoleh, nilai pheromone (pheromone count) akan didapatkan. Nilai pheromone ini akan disimpan pada routing table bersamaan dengan nilai received signal strength ( $\mathrm{RSSM})$, congestion metric $(\mathrm{CM})$, residual energy metric $(\mathrm{RM})$.

Saat node akan mengirim packet ke tujuan, node tersebut awalnya akan mengecek routing tabel yang dimilikinya. Jika di routing tabel sudah terdapat rute ke tujuan, maka packet akan dikirimkan melalui rute tersebut. Jika di routing tabel belum terdapat rute ke tujuan, maka akan dilakukan proses mencari rute dengan membroadcast Route Request ANT (REQ-ANT). Node - node tetangga yang 
menerima REQ-ANT akan membuat reverse link ke pemilik REQ-ANT. Setelah itu mereka akan menghitung nilai pheromone dan mengupdate routing tabelnya. Jika syarat - syarat dari threshold seperti yang dijelaskan sebelumnya terpenuhi, maka REQ-ANT akan direbroadcast. Proses ini akan dilakukan hingga REQ-ANT mencapai node tujuan. Node tujuan yang mendapatkan REQ-ANT akan mengupdate informasi di routing tabelnya. Setelah beberapa waktu, Node tujuan akan mendapatkan beberapa REQ-ANT yang melewati beberapa macam rute. Node tujuan akan memlih rute yang memiliki nilai pheromone yang tertinggi. Kemudian Route Reply ANT (REP-ANT) akan dikirimkan ke node sumber melalui rute tersebut. Node sumber yang menerima REP-ANT akan mengupdate routing tabelnya. Rute yang terbuat dari node sumber ke tujuan tersebut akan digunakan dalam pengiriman paket dengan mempertimbangkan nilai pheromone yang ada pada routing table.

Pada metode Enhanced-Ant DSR (S. Chatterjee and S. Das, 2015) jumlah faktor yang dipertimbangkan tidak sebanyak Enhanced-Ant AODV. Pada metode Enhanced-Ant DSR faktor residual energi tidak termasuk pada pertimbangan dalam menentukan Quality of Service (QoS). Hanya faktor congestion metric, hop count, dan link metric yang dipertimbangkan. Link Metric sendiri merupakan faktor yang pada metode Enhanced-ant AODV disebut dengan received signal strength metric. Nilai dari faktor QoS juga didapatkan dengan menggunakan equation 2 untuk Link Metric, equation 4 untuk congestion metric, dan number of hops yang pada dasarnya telah ada pada metode DSR biasa. Perhitungan nilai pheromone pada Enhanced-Ant DSR dapat dilihat pada equation 6 dibawah ini. Dimana LM adalah link metric, hop count adalah jumlah hop pada rute, dan CM adalah congeston metric.

Nilai Pheromone $=\frac{L M}{\text { Hop Count } \times C M}$

Seperti halnya pada metode Enhanced-Ant AODV, metode Enhanced-Ant DSR juga memodifikasi Route Request (RREQ) menjadi Route Request ANT (RREQ-Ant) dan Route Reply (RREP) menjadi Route Reply Ant (RREP-Ant). Meskipun RREQ-Ant dan RREP-Ant memiliki fungsi yang berbeda namun kedua kedua kontrol paket ini memiliki structure data sama. Dimana Source Address dan Destination address adalah alamat dari node sumber dan node tujuan. Hop count adalah jumlah hop, $\mathrm{CM}$ adalah congestion metric, LM adalah link metric, Type adalah tipe dari control packet (RREQ-Ant $=1$ dan RREP-Ant $=0$ ) dan Intermediate node stack adalah stack yang node penghubung dari RREQ- ant yang terproses.

Saat node akan mengirim packet ke tujuan, node tersebut akan mengecek cache dari rute yang ada. Jika rute ke tujuan belum ada maka akan dilakukan proses route discovery. Pertama node sumber akan menbroadcast kepada semua node yang dapat tercapai (reliable link). Saat node mendapatkan control packet, node tersebut akan mengecek type dari packet tersebut Jika type packet tersebut adalah RREP-Ant (Type $=0$ ) maka destination field akan dicek. Jika destination field adalah node dia sendiri maka Hop Count, CM, dan LM akan disimpan pada cache. Jika destination field bukan node dia, maka control packet akan diforward sesuai dengan Intermediate Node Address (INA) yang tersimpan. 


\section{HASIL}

Uji coba protocol Enhanced-Ant AODV dan Enhanced-Ant DSR pada MANET menggunakan NS2 versi 2.35. Pada uji coba ini digunakan Luas area sebesar 1000 x 1000m, dengan jumlah node bervariasi yaitu 50,100, dan 200 node. Gambar dari parameter uji coba dapat dilihat pada Gambar 1. Perbandingan Quality of Service (QoS) dari kedua metode ini dilakukan dengan membandingkan Packet Delivery Ratio (PDR), Packet Loss, dan End-to-end Delay.

\begin{tabular}{|c|c|}
\hline Parameter & Deskripsi \\
\hline Program Simulasi & NS 2.35 \\
\hline Sistem Operasi & Ubuntu 16.04 \\
\hline Protokol Routing & Enhanced-Ant AODV dan Enhanced Ant DSR \\
\hline Jumlah node & $50,100,200$ node \\
\hline Waktu Simulasi & 200 s \\
\hline
\end{tabular}

Gambar 1. Parameter Uji Coba

\section{Packet delivery Ratio (PDR)}

Perbandingan kinerja Packet Delivery Ratio (PDR) pada kedua protocol memperlihatkan trend yang sama yaitu dengan bertambahnya jumlah node maka nilai PDR kedua protokol mengalami penurunan. Enhanced-Ant AODV mampu mempertahankan nilai PDR diatas 0.89. Bahkan mampu mencapai nilai diatas 0.93 pada kepadatan 50 node. Sedangkan Enhanced-Ant DSR, nilai tertinggi PDR yang bisa dicapai yaitu 0.88 dan kemudian mengalami penurunan hingga dibawah 0.75 ketika jumlah node mencapai 200.

\section{Packet Loss}

Perbandingan kinerja Packet Loss pada kedua protocol yang dilakukan berdasarkan uji coba, menunjukan trend peningkatan jumlah Paket Loss ketika jumlah node ditambah. Meskipun demikian, Enhanced-Ant AODV bisa menekan jumlah Paket Loss kurang dari 13 paket pada kepadatan 50 node. Sedangkan Enhanced-Ant DSR mencapa lebih dari 22 paket pada situasi yang sama. Enhanced-Ant DSR mengalami peningkatan yang signifikan dalam jumlah Paket Loss hingga hampir lebih dari 50 paket pada 200 node. Namun dalam situasi ini, Enhanced-Ant AODV tetap bisa menjaga kestabilan Paket Loss dibawah 33 paket.

\section{End-to-end Delay}

Hasil End-to-end Delay pada kedua protocol menunjukkan bahwa trend yang sama yaitu selalu meningkat mengikuti pertambahan jumlah node pada MANETs. Selisih gap antara kedua protokol juga tetap stabil diangka 4 detik. Namun Enhanced-Ant AODV tetap lebih unggul dibandingkan Enhanced-Ant DSR.

\section{PEMBAHASAN}

Kinerja dari PDR terlihat menurun seiring dengan bertambahnya jumlah node. Hal ini terjadi karena semakin padat node, terjadinya rute rusak atau node mati lebih sering terjadi. Namun demikian metode Enhanced-Ant AODV memiliki PDR lebih tinggi daripada metode Enhanced-Ant DSR. Ini dikarenakan 
pada metode Enhanced-Ant AODV juga mempertimbangkan residual energy dari node. Dengan demikian node yang memiliki residual energy rendah atau dibawah throughput, tidak akan dipilih sebagai node penghubung (intermediate node).

Kinerja dari Packet Loss terlihat menurun seiring dengan bertambahnya jumlah node. Packet loss ini terjadi saat suatu paket tidak berhasil dikim ke node tujuan. Pada metode Enhanced-ant AODV packet loss terlihat lebih baik daripada metode Enhanced- Ant DSR. Hal ini terjadi dikarenakan pada metode Enhancedant AODV mempertimbangkan residual energy dari node, sehingga kemungkinan paket tidak dikirim karena node penghubung mati (kehabisan energi) bisa dikurangi.

End-to-end Delay terlihat bertambah saat jumlah node juga bertambah. Meskipun metode Enhanced-Ant AODV terlihat lebih baik dibandingkan metode Enhanced-Ant DSR, perbedaan dan penurunan kinerjanya tidak terlihat signifikan. Hal ini terjadi karena kedua metode sudah sama - sama menerapkan peniliaian terhadap congestion (keramaian) dari suatu node. Dengan hal ini pemilihan rute dengan congestion yang tinggi dapat diminimalisir.

\section{KESIMPULAN}

Hasil uji coba dengan melakukan perubahan node dari 50,100, 200 menunjukkan bahwa kinerja dari Enhanced-Ant AODV lebih baik dair EnhancedAnt DSR. Hal ini terjadi karena pada perhitungan pheromone count pada Enhanced-ant AODV mempertimbangkan 4 hal yaitu received signal strength (RSS), congestion metric, residual energy dan hop count. Sedangkan Enhancedant DSR hanya mempertimbangkan 3 faktor yaitu link metric (RSS), congestion metric, dan hop count. Dengan tidak mempertimbagnkannya Enhanced-Ant DSR terhadap residual energy maka kemungkinan terjadinya node mati karena memiliki residual energy yang rendah lebih sering terjadi

\section{SARAN}

Penelitian ini masih memiliki ruang pengembangan yang sangat terbuka. Salah satu contohnya yaitu dengan melakukan uji coba yang lebih bervariatif tehadap faktor kecepatan node, jumlah koneksi, tipe koneksi TCP/UDP, data transmission rate dan sekuritas.

\section{DAFTAR RUJUKAN}

A. Zakaria, E. Setijadi, I. K. E. Purnama, and M. H. Purnomo. 2018. "Analisis Kinerja Protokol Routing AODV, DSR, dan OLSR pada Mobile Ad hoc Network Berdasarkan Parameter Quality of Service," J. Rekayasa Elektr., vol. 14 , no. 3 .

C. Perkins, E. Belding-Royer, and S. Das. 1999. "Ad hoc on demand distance vector (AODV) routing," in Proc. Of the 2nd IEEE Workshop on Mobile Computing Systems and Applications (WMCSA), New Orleans, LA, vol. 6, no. 7, pp. 90-100.

D. Sarkar, S. Choudhury, and A. Majumder. 2018. "Enhanced-Ant-AODV for optimal route selection in mobile ad-hoc network," J. King Saud Univ. Comput. Inf. Sci. 
M. Bouhorma, H. Bentaouit, and A. Boudhir. 2009. "Performance comparison of ad-hoc routing protocols AODV and DSR," Int. Conf. Multimed. Comput. Syst. -Proceedings, pp. 511-514.

S. Chatterjee and S. Das. 2015. "Ant colony optimization based enhanced dynamic source routing algorithm for mobile Ad-hoc network," Inf. Sci. (Ny)., vol. 295, pp. 67-90. 